\title{
Post-liver transplantation diabetes mellitus - a clinical challenge for diabetologists?
}

\author{
Sanjay K. Bhadada ${ }^{1} \cdot$ Rimesh Pal $^{1}$ \\ Published online: 26 May 2021 \\ (C) Research Society for Study of Diabetes in India 2021
}

Liver transplantation has become an effective therapy for patients with acute or chronic end-stage liver disease. With improvement in operative techniques and immunosuppressive regimens, long-term survival after liver transplantation has markedly increased. However, with increased longevity, the attention has shifted towards long-term complications, which are primarily related to the immunosuppressive treatment. One such complication is new-onset diabetes after transplantation (NODAT), often referred to as posttransplantation diabetes mellitus (PTDM).

New-onset diabetes after transplantation refers to individuals who develop new-onset diabetes following solid organ, bone marrow, and hematopoietic stem cell transplant. It characteristically excludes patients with pretransplant diabetes that remained undiagnosed and posttransplant hyperglycemia that resolves by the time of discharge [1]. On the other hand, PTDM theoretically describes the presence of diabetes in the posttransplant setting irrespective of the time of onset of diabetes $[1,2]$. Nevertheless, in routine clinical practice, the two terms are often used interchangeably.

Hyperglycemia is not uncommon during the early posttransplant period; nearly $90 \%$ of liver transplant recipients exhibit hyperglycemia in the immediate posttransplant period [3]. In the majority of the cases, such stress- or steroid-induced hyperglycemia resolves by the time of discharge. Whereas posttransplantation hyperglycemia is an important risk factor for subsequent PTDM, a formal diagnosis of PTDM should ideally be made once the patient is stable on maintenance immunosuppression and in the absence of acute infection [4].

The diagnosis of PTDM, which in the context of liver transplantation is referred to as post-liver transplantation diabetes mellitus (PLTDM), has long been a matter of debate [5].

Sanjay K. Bhadada

bhadadask@rediffmail.com

1 Department of Endocrinology, Post Graduate Institute of Medical Education and Research, Chandigarh, Chandigarh 160012, India
Earlier, the most commonly used clinical definition was the requirement of insulin for a minimum period (usually 30 days) posttransplantation. This definition had resulted in underestimating the prevalence of diabetes after transplantation because it excludes patients treated with oral antidiabetic drugs and those with untreated hyperglycemia, impaired fasting glucose (IFG), or impaired glucose tolerance (IGT). Furthermore, it does not distinguish between patients with new-onset disease from those with preexisting disease [6].

The International Consensus Guidelines on new-onset diabetes after transplantation 2003 recommended that the diagnosis should be based on the American Diabetes Association (ADA) criteria for type 2 diabetes mellitus [6], which are as follows:

- Fasting plasma glucose (FPG) $\geq 7.0 \mathrm{mmol} / \mathrm{l}(126 \mathrm{mg} / \mathrm{dl})$ with no calorie intake for at least $8 \mathrm{~h}$, or

- Two-hour plasma glucose during an OGTT (2-h PG postOGTT $) \geq 11.1 \mathrm{mmol} / \mathrm{l}(200 \mathrm{mg} / \mathrm{dl})$, or

- Casual plasma glucose $\geq 11.1 \mathrm{mmol} / \mathrm{l}(200 \mathrm{mg} / \mathrm{dl})$ with classic symptoms of diabetes, all being documented on 2 different occasions.

Thus, the diagnostic criteria for PLTDM are the same as those for diabetes in the general population [5]. Since postprandial hyperglycemia is much more prevalent than fasting hyperglycemia among liver transplant patients [7], the ideal screening test for PLTDM is the oral glucose tolerance test (OGTT) [8]. However, performing an OGTT under supervision might not always be feasible, thereby clinicians might have to rely solely on FPG.

Even in the posttransplant setting, a fasting plasma glucose level of $<5.5 \mathrm{mmol} / \mathrm{l}(100 \mathrm{mg} / \mathrm{dl})$ is considered to be normal, and $5.5-6.9 \mathrm{mmol} / \mathrm{l}(100-125 \mathrm{mg} / \mathrm{dl})$ is considered to be IFG. A 2-h post-OGTT plasma glucose level of $<7.7 \mathrm{mmol} / \mathrm{l}$ (140 $\mathrm{mg} / \mathrm{dl})$ is considered to be normal, and 7.7-11.1 mmol/1 (140$199 \mathrm{mg} / \mathrm{dl}$ ) is considered to be IGT. The importance of diagnosing the pre-diabetic states (IFG and IGT) in the post-liver 
transplant context lies in their relevance as predictors of future risk of PLTDM [5]. Apart from the aforementioned diagnostic criteria, post-liver transplant patients whose blood glucose levels are normal but are using insulin or oral antidiabetic drugs are also diagnosed as having PLTDM [9].

Glycated hemoglobin $\left(H b A_{I c}\right)$ has a limited role in the diagnosis of PTDM (or PLTDM). Due to blood loss associated with the transplant procedure, preexisting anemia (and subsequent shortened red blood cell survival), and especially lack of robust evidence regarding its use in the early posttransplant period, $\mathrm{HbA}_{1 \mathrm{c}}$ is not recommended as a first-line diagnostic test for PLTDM, especially in the first 3 months posttransplant [10]. Beyond 3 months, the new hemoglobin would be synthesized and glycated for an appropriate period of time; in such setting, $\mathrm{HbA}_{1 \mathrm{c}} \geq 6.5 \%$ can be utilized to diagnose PTDM. On the contrary, many studies do not recommend the use of $\mathrm{HbA}_{1 \mathrm{c}}$ alone as a screening tool for diagnosing PTDM in the first year after transplant [11].

Although the diagnostic criteria for defining PLTDM have been standardized, the timing of the tests remains controversial and unresolved. Most believe that the first month after liver transplantation still falls within the period of surgical stress; hence, plasma glucose levels beyond 1 month after liver transplantation should be used as the determining criterion $[9,12]$. On the contrary, others opine that if rejection or surgical complications do not occur in the postoperative period, stress-related hyperglycemia would be resolved in most patients until the end of the first month [13].

In this issue of the International Journal of Diabetes in Developing Countries, Topaloğlu et al. report on the prevalence of NODAT after liver transplantation in patients with acute liver failure. The diagnosis of NODAT was based solely on fasting blood glucose (FBG) measured at frequent time intervals. Accordingly, the prevalence of NODAT was $26.98 \%, 14.54 \%$, and $8.3 \%$ based on FBG measured at 1 month, 3 months, and 12 months post-liver transplant, respectively [14]. Although a significant fraction of patients who were alive at $1^{\text {st }}$ month had subsequently succumbed at the $3^{\text {rd }}$ month and $12^{\text {th }}$ month, it remains unclear whether NODAT diagnosed in the $1^{\text {st }}$ month could have been one of the predisposing factors contributing to the later demise of the patients. Similarly, it remains unanswered whether the marked decline in the prevalence of NODAT at the $3^{\text {rd }}$ and $12^{\text {th }}$ month could have resulted from the selective demise of patients diagnosed with NODAT in the $1^{\text {st }}$ month, or a spontaneous reversal of stress-related hyperglycemia with time.

Thus, it does not seem to be prudent to label a liver transplant recipient as having NODAT on the basis of blood glucose values measured as early as 1 month posttransplant. The diagnosis of NODAT (or PLTDM) should ideally be based on 2-h PG post-OGTT (or FPG) or need for insulin/antidiabetic drugs beyond 1 month after liver transplant. Nevertheless, putting aside semantics, appropriate management of any degree of hyperglycemia in the posttransplant period is imperative as those with early perioperative hyperglycemia and PTDM have higher rates of graft rejection, infection, and rehospitalization $[4,15,16]$.

Data derived from randomized controlled trials on the short- and long-term use of anti-hyperglycemic agents in the setting of PTDM is limited. Insulin remains the agent of choice for the management of hyperglycemia, PTDM, preexisting diabetes and diabetes in the hospital setting. After discharge, PTDM patients with poor glucose control should continue insulin with frequent home self-monitoring of blood glucose to help titrate insulin doses accordingly [4].

Hitherto, there is insubstantial data on the use of noninsulin agents in the context of PTDM. The choice of an appropriate agent is usually made after taking into consideration the side effect profile of the drug and possible interactions with the patient's ongoing immunosuppression regimen. Frequent drug dose adjustments may be needed because of a decline in the glomerular filtration rate, a common complication in transplant patients. A short-term pilot study reported the use of metformin in renal transplant recipients, but the same has not been replicated in other types of organ transplant [17]. Thiazolidinediones have been successfully used in patients with liver and renal transplants; however, frequent side effects that include fluid retention, heart failure, and osteopenia limit its use in the posttransplant setting $[18,19]$. Dipeptidyl peptidase-4 inhibitors (DPP4i) have demonstrated safety in some recent clinical trials [20,21]. Besides, DPP4i do not interact with most immunosuppressant drugs and hence can be safely used in most PTDM patients. Nevertheless, in view of limited clinical data, it would not be prudent to advise one antidiabetic drug (noninsulin) over the other. Well-designed randomized controlled trials examining the efficacy and safety of these and other antidiabetic agents in patients with PTDM are needed.

\section{Declarations}

Ethical approval Not required

Informed consent Not applicable

Conflict of interest The authors declare no competing interests.

\section{References}

1. Sharif A, Hecking M, de Vries APJ, Porrini E, Hornum M, RasoulRockenschaub S, et al. Proceedings from an international consensus meeting on posttransplantation diabetes mellitus: recommendations and future directions. Am J Transplant Off J Am Soc Transplant Am Soc Transpl Surg. 2014;14:1992-2000.

2. Hecking M, Werzowa J, Haidinger M, Hörl WH, Pascual J, Budde K, et al. Novel views on new-onset diabetes after transplantation: development, prevention and treatment. Nephrol 
Dial Transplant Off Publ Eur Dial Transpl Assoc - Eur Ren Assoc. 2013;28:550-66.

3. Werner KT, Mackey PA, Castro JC, Carey EJ, Chakkera HA, Cook CB. Hyperglycemia during the immediate period following liver transplantation. Future Sci OA. 2016;2:FSO97.

4. American Diabetes Association. 2. Classification and diagnosis of diabetes: Standards of Medical Care in Diabetes-2021. Diabetes Care. 2021;44:S15-33.

5. Peláez-Jaramillo MJ, Cárdenas-Mojica AA, Gaete PV, Mendivil CO. Post-liver transplantation diabetes mellitus: a review of relevance and approach to treatment. Diabetes Ther. 2018;9:521-43.

6. Davidson J, Wilkinson A, Dantal J, Dotta F, Haller H, Hernandez D, et al. New-onset diabetes after transplantation: 2003 International Consensus Guidelines. Transplantation. 2003;75:SS3-24.

7. Ducloux D. Polycystic kidney disease as a risk factor for posttransplant diabetes mellitus. Nephrol Dial Transplant. 1999;14: 1244-6.

8. Shivaswamy V, Boerner B, Larsen J. Post-transplant diabetes mellitus: causes, treatment, and impact on outcomes. Endocr Rev. 2016;37:37-61.

9. Ling Q, Xie H, Lu D, Wei X, Gao F, Zhou L, et al. Association between donor and recipient TCF7L2 gene polymorphisms and the risk of new-onset diabetes mellitus after liver transplantation in a Han Chinese population. J Hepatol. 2013;58:271-7.

10. John PR, Thuluvath PJ. Outcome of patients with new-onset diabetes mellitus after liver transplantation compared with those without diabetes mellitus. Liver Transplant Off Publ Am Assoc Study Liver Dis Int Liver Transplant Soc. 2002;8:708-13.

11. Solhjoo M, Kumar SC. New onset diabetes after transplant. StatPearls. Treasure Island (FL): StatPearls Publishing; 2021. [cited 2021 Apr 21]. Available from: http://www.ncbi.nlm.nih.gov/ books/NBK544220/

12. Chaoyang LV, Zhang Y, Chen X, Huang X, Xue M, Sun Q, et al. New-onset diabetes after liver transplantation and its impact on complications and patient survival. J Diabetes. 2015;7:881-90.
13. Lane JT, Dagogo-Jack S. Approach to the patient with new-onset diabetes after transplant (NODAT). J Clin Endocrinol Metab. 2011;96:3289-97.

14. Topaloğlu Ö, Cengiz M, Cengiz A, Evren B, Yoloğlu S, Yılmaz S, et al. New-onset diabetes mellitus after liver transplantation in the patients with acute liver failure. Int J Diabetes Dev Ctries. 2021 [cited 2021 Apr 18]; Available from: http://link.springer.com/10. 1007/s13410-021-00922-y.

15. Thomas MC, Moran J, Mathew TH, Russ GR, Rao MM. Early perioperative hyperglycaemia and renal allograft rejection in patients without diabetes. BMC Nephrol. 2000;1:1.

16. Wallia A, Illuri V, Molitch ME. Diabetes care after transplant. Med Clin North Am. 2016;100:535-50.

17. Kurian B, Joshi R, Helmuth A. Effectiveness and long-term safety of thiazolidinediones and metformin in renal transplant recipients. Endocr Pract. 2008;14:979-84.

18. Budde K, Neumayer H-H, Fritsche L, Sulowicz W, Stompôr T, Eckland D. The pharmacokinetics of pioglitazone in patients with impaired renal function. Br J Clin Pharmacol. 2003;55:368-74.

19. Luther P, Baldwin D. Pioglitazone in the management of diabetes mellitus after transplantation. Am J Transplant Off J Am Soc Transplant Am Soc Transpl Surg. 2004;4:2135-8.

20. Lane JT, Odegaard DE, Haire CE, Collier DS, Wrenshall LE, Stevens RB. Sitagliptin therapy in kidney transplant recipients with new-onset diabetes after transplantation. Transplantation. 2011;92:e56-7.

21. Strøm Halden TA, Åsberg A, Vik K, Hartmann A, Jenssen T. Short-term efficacy and safety of sitagliptin treatment in longterm stable renal recipients with new-onset diabetes after transplantation. Nephrol Dial Transplant. 2014;29:926-33.

Publisher's note Springer Nature remains neutral with regard to jurisdictional claims in published maps and institutional affiliations. 